\title{
Characterization of Small Scale Farmers' Low Levels of Adoption to Crop Insurance as an Adaptation Strategy to Climate Variability in Nyandarua County of Kenya
}

\author{
David I. Muriithi ${ }^{*}$, Boniface N. Wambua ${ }^{2}$ and Kennedy J. Omoke ${ }^{2}$ \\ ${ }^{1} \mathrm{PhD}$ Student, University of Nairobi, Department of Geography and Environmental Studies, \\ Kiriaini, Kenya \\ *Corresponding author's email: davidikua44 [AT] gmail.com

\begin{abstract}
${ }^{2}$ Senior Lecturer \& Chairman, University of Nairobi, Department of Geography and Environmental Studies
Nairobi, Kenya

Email: wambua_boniface [AT] uonbi.ac.ke
\end{abstract} \\ ${ }^{2}$ Senior Lecturer, University of Nairobi, Department of Geography and Environmental Studies \\ Nairobi, Kenya \\ Email: jkomoke [AT] uonbi.ac.ke
}

\begin{abstract}
Kenya is one of the many countries in Sub Saharan Africa affected by climate variability and its related hazards due to changes in temperature and variations in rainfall in most parts of the country. The present study has been undertaken to assess the adaptation strategies applied by the small scale farmers in response to climate variability in Nyandarua County. The study has been conducted in central region of Kenya which is relatively humid and good for agricultural production. A total sample size of 300 respondents from five sub counties was used to collect the primary data through the random sampling technique. Descriptive Likert analysis and Inferential binary logit regression was used to assess the factors affecting the willingness to adopt crop insurance to mitigate the risks of variability of climate on crop farming. The results of the study indicate that adoption of crop insurance scored very low in relation to other adaptation strategies. The logit regression model on the other hand revealed that age and marital status was positively significant with willingness to adopt crop insurance while the marginal effects of levels of income and monthly income implied that the likelihood of willingness to adapt crop insurance increased by 1.32 times and 13.3 percent respectively. Based on the study findings, if small scale farmers are well supported to adopt crop insurance, then this adaptation strategy can be among the most effective strategies in Kenya. However, due to low adaptive capacity, more awareness needs to be created on the importance and procedures of obtaining the specific agricultural insurance covers. The study concludes that modern adaptation approaches are important in presence of formal crop insurance policies especially in the rural areas of Kenya.
\end{abstract}

Keywords---- Climate variability; adaptation strategies; crop insurance; binary logit model

\section{INTRODUCTION}

Recent studies in agricultural production have found out that climate variability pose great challenges to agricultural output which vary from region to region and type of agricultural systems (Malik et al. 2010). In order to reduce the crop output losses and maximize the current agricultural output, adaptations in crop management will no doubt be required (IPCC 2007). Adaptation strategies can broadly be divided into two groups i.e. short-term and long-term adaptations (Bryant et al., 2000). Short term adaptations is where the farmers commonly select some measures autonomously as a result of the current observed climatic changes based on the past experiences and knowledge they have (Holzkämper, 2017).Transformative long term strategies on the other hand requires proper planning which are also systematically implemented on a wider spatial scale (Holzkämper, 2017).

The adaptation strategies commonly undertaken by small scale farmers often emanate from policies undertaken by public and private actors (Hassan and Nhemachena, 2008). These range of actors ensures that proper adaptation measures related to climate variability are well implemented systematically by considering the investments in infrastructure and technologies as well as behavioral changes (Adger et al., n.d.). Developing countries like Kenya have registered a long record of strategies undertaken to adapt to the negative effects of climate variations especially in crop farming (Mikalitsa, 2010). Small scale farmers in Kenya and especially in the dry areas have been observed to have undertaken a range of crop based adaptation measures to caution them against the risks of crop output losses (Wambua et al., 2014). These adaptations 
strategies includes adjusting planting periods, land management and soil conservation practices, irrigation, crop diversification, water management and crop insurance. (Muriithi DI, 2020).

The ongoing international treaties and conventions on climate change have mounted great pressure on the Kenyan government to protect the small scale farmers livelihoods against the impacts of local climate variability (Simotwo et al., 2018). Majority of small scale farmers in Kenya are poor and their limited capital reduces the amount of disposable resources they can invest in proper adaptation activities (Oluoko-Odingo 2011). These challenges make the small small scale farmers to come up with poor decisions regarding the most appropriate adaptation measures and proper timing to apply them(Sen et al., 2020). These challenges increase small scale farmers' vulnerability to climate variation (Wambua et al. 2008). Past studies have shown that in order for the various actors to reduce the negative effects associated with climate variability, it is important for the policy makers to evaluate how small scale farmers can presently prepare for future climate variability adaptations (Deressa et al, 2010).This evaluation can only be done by properly understanding the current small scale farmers' levels of resilience (Rakib, 2014).

One of the more promising proposals for reforming the crop farming sector against the effects of climate variability is crop insurance programs(Sen et al., 2020). However this adaptation strategy is greatly influenced by willingness and ability to adopt crop Insurance as an adaptation strategy. This creates a gap for this study

\section{STUDY AREA}

Nyandarua County lies within the equatorial climatic region of Kenya experiencing low to moderate temperatures. The lowest temperatures have been documented in the months of July with the average mean temperature going below $12^{\circ} \mathrm{c}$. On the other hand, the highest temperatures recorded have been in the month of December with the mean temperature rising up to $25^{\circ} \mathrm{c}$. During the periods of clear nights, the cold air rises in the slopes of Aberdare ranges and flows down the west of plateaus valleys where temperatures fall up to $-1.3^{0} \mathrm{C}$ for a short time before the sun rises. The county receives two bimodal rainfall seasons with short rains from September to December with $700 \mathrm{~mm}$ as maximum rainfall and long rains from the month of March to May with a maximum of 1600mm (Omwoyo and Akivaga, 2015). The county is known for major crops such as maize, wheat, vegetables and Irish potatoes. These crops are not entirely for subsistence because some are sold to account for a substantial income for most of the households (Kaguongo, et al., 2007). The entire arable land in Nyandarua is $184,900.0$ ha but only 96,062 ha land is under cultivation. The recent climatic conditions have shown that some parts of the County are receiving periods of dry spells and very low temperatures at times leading to crops failure and reduced crop yields (Jaetzold et al., 2007).

\section{MATERIALS AND METHODS}

\subsection{Descriptive and Likert Scaling Method}

Likert-type scaling has widely been used in the field of social science studies. In a Likert-type scaling, respondents were asked to indicate degree of each statement in terms of how they perceived the effectiveness of crop insurance as an adaptation strategy. This study used four degrees of agreement or disagreement and coded the scaling as very effective (4), effective (3), less effective (2) and not effective (1). The data was collected for the nine adaptation strategies which were relevant to this study. The Likert scaling for this particular study was used to express definite favorableness or not favorableness by the respondents about different adaptation strategies adopted.

\subsection{Inferential Binary Logistic Regression Model}

Logistic regression model has widely been used in social sciences to investigate the relationship between ordinal or categorical response probabilities and categorical variables (Stephan, 2015). This model was preferred in this study since it has been widely adopted from 1960s due to advantage in dealing with discrete variable outcome (Thoai et al 2018). The general formula of the binary logit model is expressed by the following formula;-

$$
\text { 1. Logit }(P)=X \beta=\beta_{0}+\beta_{1} X_{1}+\beta_{2} X_{2}+\ldots \ldots \ldots \ldots \ldots \beta_{K} X_{K}
$$

Where-;

$X \beta$ is the probability of achieving the dependent variable $\mathrm{Y}$ given a set of independent variables

$$
\text { 2. } \quad P_{1}\left(Y_{1}=1\right) \frac{e x \beta}{1+e x \beta}
$$

$\beta_{0=}$ Indicates $\log$ odds ratio

3. $X_{\beta}=\beta_{0}+\sum_{i=1}^{n} \beta_{i} X_{k i}$

$X_{1}, X_{2}, X_{3} \ldots \ldots \ldots \ldots \ldots X_{K}$; Refers to the probability of the explanatory or independent variables. Reporting of the logistic regression model is done by stating the odds Ratio $=\operatorname{Exp}(\beta)$, Coefficient of marginal effect $(M E)$, Significance levels $(P)$. 
An odds ratio represents how much likely variable $Y=1$ is related to variable $Y=0$, given a set of independent variables $X_{1} \ldots \ldots . X_{K}$. In this study, the odds ratio has been used to determine the likelihood of the sample respondent adopting crop insurance compared to not adopting crop insurance based on some socio economic characteristics of the small scale farmers i.e. age, marital status, level of income and level of education. The logit model was constructed from 300 small scale farmers who were asked whether they had adopted crop insurance as an adaptation strategy and analyzed using SPSS version 14.0. The response of this question was discrete (either Yes $=1$ or $\mathrm{No}=2$ ). Age of the respondents was measured in years which were put in categories. It was assumed that an increase in age bracket increased the likelihood of adopting the crop insurance, likewise education levels. Small scale farmers with higher education levels were assumed to be knowledgeable about insurance options and therefore likely to adopt crop insurance much better than those with lower education levels. Higher incomes and male headed households were also hypothesized to increase the probability of adopting crop insurance as an adaptation strategy.

\section{RESULTS AND DISCUSSION}

\subsection{Socio-economic characteristics of the sampled small scale farmers}

The age bracket that recorded the highest respondents was 46-55 years (25.42\%) followed by $36-45$ years (23.75\%). Respondents aged below 25 years recorded the lowest response of $9.03 \%$ while one respondent $(0.3 \%)$ declined to give his age. Out of the 300 questionnaires administered, 191 (63.67\%) respondents were male and $106(36.33 \%)$ respondents were females. However there was none who reported as being trans-gender or failed to report the gender. Regarding to this variable, majority $223(74.3 \%)$ of the respondents were married while $75(25 \%)$ were single. However due to sensitivity of the question, $2(0.7 \%)$ respondents declined to declare their status. This variable description could mean that the small scale farmers were settled in the county with stable families and therefore labour mobility was less.

Table 1: Marital status of the respondent

\begin{tabular}{lccc}
\hline Marital status of the respondent & Frequency & Percentage & Cumulative \% \\
\hline Single & 75 & 25.0 & 25.0 \\
Married & 223 & 74.3 & 99.3 \\
No response & 2 & 0.7 & 100.0 \\
Total & 300 & 100.0 & \\
\hline
\end{tabular}

Source: Author 2020

Results of the study showed that farming is the major source of income among the small scale farmers in Nyandarua County while casual labour is the least source of income. However, majority of the respondents said that they have more than one income source revealing that they had engaged in income diversification. In addition, majority of the respondents reported that their monthly income was below Kshs. 10,000. This income level was perceived to be low and therefore it was anticipated that it could be one of the challenges/limitations that would hamper proper and effective adaptations to climate variability.

Table 2: Level of income

\begin{tabular}{lccc}
\hline Monthly income in Ksh. & Frequency & Percentage & Cumulative \% \\
\hline$<10,000$ & 114 & 38.0 & 38.0 \\
$10,001-20,000$ & 95 & 31.7 & 69.7 \\
$20,001-30,000$ & 40 & 13.3 & 83.0 \\
$30,001-50,000$ & 44 & 14.7 & 97.7 \\
$>50,0001$ & 7 & 2.3 & 100.0 \\
Total & 300 & 100.0 & \\
\hline
\end{tabular}

Source: Author 2020

From the results, the researcher established that most of the small scale farmers had attained significant levels of education which was anticipated that it could have had some positive contribution to adaptation; Secondary level (43.33\%), College level (20\%), and University level $(11.3 \%)$. Low levels of education $(25 \%)$ could have been attributed to by high drop out at primary level especially for girls due to early pregnancies and early marriages (Glennerster, et al., 2011).

\subsection{Climate variability preparedness and adaptation measures}

About $13.1 \%$ of the respondent said they had changed planting dates as an adaptation strategy. About $20.3 \%$ of the respondent cultivated different crop varieties which were perceived to be more resistant to variations in climate. Crop diversification had been adopted by the majority of small scale farmers (20.3\%). About $13.1 \%$ of small scale farmers had decided to apply some crop irrigation to improve the crop yields while $4.9 \%$ of respondent perceived the search for offfarm jobs i.e. income diversification as an adaptation strategy. Green house technology and crop insurance registered the 
lowest score of adaptation of $5.9 \%$ and $2.1 \%$ respectively. $15.2 \%$ of the respondents indicated that they had used other adaptation strategies that were captured by the questionnaire as descriptive and open ended responses. These strategies included; agroforestry, mixed cropping, increasing size of cultivatable areas of land, switching from crops to livestock and fertilizers and manure application for soil conservation strategies.

Table 3: Adaptation strategies applied by the respondents

\begin{tabular}{lcrr}
\hline Adaptation strategy & Frequency & Percentage & Cumulative \% \\
\hline Crops diversification & 87 & 20.28 & 20.28 \\
New crop variety & 87 & 20.28 & 40.56 \\
Other adaptations technique & 65 & 15.15 & 55.71 \\
Use of crop irrigation & 56 & 13.05 & 68.76 \\
Adjusting planting dates & 56 & 13.05 & 81.81 \\
Greenhouse technology & 25 & 5.83 & 87.64 \\
No response & 23 & 5.36 & 93 \\
Income diversification & 21 & 4.9 & 97.9 \\
$*$ Crop insurance & 9 & 2.1 & 100 \\
Total & $\mathbf{4 2 9}$ & $\mathbf{1 0 0}$ & \\
\hline
\end{tabular}

- *Adaptation strategy subjected to Logistic Regression Analysis

- $\quad$ Notes: Multiple responses reported

Source: Researcher 2020

\subsection{Small scale farmers' perceptions about the effectiveness of the adaptation measures adopted}

The results of the perceptions about the effectiveness of the adaptation strategies adopted in improving the crop yields were presented in the table below. The likert scale analysis indicated that crops diversification and planting new crops varieties that were resistant to climate variability and its related effects were the most effective perceived adaptation strategies. Adoption of crop insurance in this case recorded the lowest standard deviation of 0.17 with 8 out 9 respondents who had adopted it perceiving it as an effective strategy to caution farmers against loss arising from adverse climatic variations. Based on these findings, it is evident that if many small scale farmers are willing and able to adopt crop insurance, then this strategy can be among the most effective strategy. However, due to low adaptive capacity for this strategy, more awareness need to be created on the relevant and procedures of obtaining the specific agricultural insurance covers.

Table 4: Likert scale for the perception count of the effectiveness of the adaptation strategies

\begin{tabular}{lcllllll}
\hline Adaptation strategy & $\begin{array}{l}\text { Very } \\
\text { effective }\end{array}$ & Effective & $\begin{array}{l}\text { Less } \\
\text { effective }\end{array}$ & $\begin{array}{l}\text { Not } \\
\text { effective }\end{array}$ & Total & Mean & S.D \\
\hline Crops diversification & 15 & 55 & 2 & 15 & 87 & 1.71 & 0.45 \\
New crop variety & 16 & 50 & 1 & 20 & 87 & 1.71 & 0.45 \\
Use of crop irrigation & 12 & 38 & 0 & 6 & 56 & 1.81 & 0.39 \\
Adjusting planting dates & 7 & 24 & 2 & 23 & 56 & 1.81 & 0.39 \\
Greenhouse technology & 7 & 17 & 1 & 0 & 25 & 1.92 & 0.27 \\
Income diversification & 1 & 13 & 1 & 16 & 31 & 1.93 & 0.26 \\
*Crop insurance & 2 & 6 & 1 & 0 & 9 & 1.97 & 0.17 \\
\hline
\end{tabular}

- *Adaptation strategy subjected to Logistic Regression Analysis

- $\quad$ Notes: Multiple responses reported

Source: Researcher 2020

\subsection{Results of the Binary Logit Model for crop insurance adaptation strategy}

The result of the response on willingness to adopt crop insurance adaptation strategy by the sample respondents was given in Table 6. It is indicated that only 3 percent of the farmers' were willing to adopt crop insurance adaptation strategy and 97 percent of the farmers' were not interested to participate in the adaptation strategy. Results of the binary logit model found that the $\mathrm{LR} \chi 2$ was statistically significant at 0.05 percent level $(\mathrm{P}=0.948)$. This significant level indicated that the overall relationship between the explanatory indicators and the probability of adopting crop insurance to combat the effect of climate variability was not statistically significant. The value of Pseudo $\mathrm{R}^{2}$ was 0.015 revealed that all the explanatory variables explained 1.5 percent of the probability that farmers would adopt crop insurance for climate variability as and adaptive mechanism (Table 6).

From the results of binary logit model, age of the sample household was positive and not significant at 5 percent. This implied that an increase in age from one bracket to the other increased the probability of adopting crop insurance at 
a rate at 155.6 percent since the elder farmers were more interested to adopt crop insurance. On the other hand, the coefficient of education was negative $(-0.482)$ and insignificant association $(\mathrm{P}=0.250)$ with willingness to adopt crop insurance to mitigate the impacts of climate variability. The marginal effect of education indicated that the probability of willingness to adopt crop insurance by sample farmers was increased by 132.2 percent since the educated farmers' were well aware of crop insurance to avoid the risk. The results also showed that marital status among the respondents was positively significant and its marginal effects implied that the probability of willingness to adopt crop insurance by women increased by 1.2 percent similar to the study conducted by Ngigi (2017). Level of income coefficient was found to be 0.199 which meant that lower incomes increased the probability of adopting crop insurance by $13.3 \%$. In conclusion, the overall marginal effects indicated that the probability of prediction was 421 percent for willingness to adopt crop insurance to reduce the impacts of climate variability on crop farming. These findings were similar to Sarwary et al., (2020).

The results of odds ratio for those variables which have one or more than one indicates that the likelihood of happening the event on willingness to adopt crop insurance will be more than the non-happening of event. The variables which are having more than one odds ratio were age (1.501) and marital status (1.088) increased the chances of probability of sample respondents for willingness to adopt crop insurance as climate variability adaptive strategy.

Table 5: Response on adoption of crop insurance as an adaptation strategy

\begin{tabular}{lrrrrr}
\hline \multicolumn{1}{c}{ Adopted crop insurance } & & & & \\
& & Frequency & Percent & Valid Percent & Cumulative Percent \\
\hline Valid & Yes (1) & 9 & 3.0 & 3.0 & 3.0 \\
& No (2) & 291 & 97.0 & 97.0 & 100.0 \\
& Total & 300 & 100.0 & 100.0 & \\
\hline
\end{tabular}

Source: Researcher 2020

Table 6: Estimated results of the binary logit model for adoption of crop insurance

\begin{tabular}{lcllll}
\hline Indicator & Coefficients & $\begin{array}{l}\text { Std. } \\
\text { Error }\end{array}$ & P-value & Marginal effects (ME) & Odds ratio \\
\hline Age & 0.406 & 0.325 & 0.212 & 1.556 & 1.501 \\
Marital status & 0.085 & 0.775 & 0.913 & 0.012 & 1.088 \\
Level of income & -0.119 & 0.325 & 0.715 & 0.133 & 0.880 \\
Level of education & -0.482 & 0.419 & 0.250 & 1.322 & -618 \\
Constant & 3.750 & 1.828 & 0.040 & - & - \\
Log likelihood & 43.431 & - & - & - & - \\
LR $\chi 2$ & 0.948 & - & - & - & - \\
Prob $>\chi 2$ & 0.948 & - & - & - & - \\
Pseudo R & 0.015 & - & - & - & - \\
Overall ME & - & - & - & 4.211 & - \\
\hline
\end{tabular}

Source: Author's computations 2020

\section{CONCLUSION AND POLICY RECOMMENDATIONS}

The small scale farmers scored poorly in certain climate change adaptation activities like embracing crop insurance (1.3\%). The findings were similar to results of a study done by Limo (2013) where none of the respondents had ever adopted crop insurance as an adaptation measure to climate variability. However, based on the Likert scale analysis, it is evident that if many small scale farmers are willing and able to adopt crop insurance, then this strategy can be among the most effective strategies in crop farming. Crop insurance is one of the financial adaptation options that small scale farmers should use to reduce the climate-related risk of income loss. However, this strategy should be supported by the government by providing inducement programs that greatly influence small scale farmers' financial management pronouncements. The research findings uphold those of Dercon, (2002) that the modern adaptation approaches are important in presence of formal insurance especially in the rural areas. This is because this approach can influence the wellbeing of small scale farmers by safeguarding and protecting their assets in times of adverse weather conditions. Limited awareness and lack of information about the relevant insurance products and procedures was cited by $22 \%$ of respondents as one of the major hindrances to adoption of this adaptation strategy.

\section{COMPETING INTERESTS}

Authors have declared that no competing interests exist. 


\section{AUTHORS' CONTRIBUTIONS AND ACKNOWLEDGMENT}

This work was carried out by author ${ }^{1}$ under the guidance and supervision of authors ${ }^{2}$. Author ${ }^{1}$ conducted the study, executed the statistical analysis and composed the draft of the manuscript.

\section{REFERENCES}

1. Adger, W. N., Agrawala, S., Mirza, M. M. Q., Conde, C., O’Brien, K., Pulhin, J., Pulwarty, R., Smit, B.,Takahashi, K., Enright, B., Fankhauser, S., Ford, J., Gigli, S., Jetté-Nantel, S., Klein, R. J. T., Pearce, T. D., Shreshtha, A., Shukla, P. R., Smith, J. B., ... Magalhães, A. R. (n.d.). Assessment of adaptation practices, options, constraints and capacity. 28.

2. Bryant, C. R., Smit, B., Brklacich, M., Johnston, T. R., Smithers, J., Chiotti, Q., \& Singh, B. (2000). Adaptation in Canadian Agriculture to Climatic Variability and Change. In S. M. Kane \& G. W. Yohe (Eds.), Societal Adaptation to Climate Variability and Change (pp. 181-201). Springer Netherlands. https://doi.org/10.1007/978-94-017-3010$5 \_10$

3. Dercon, S. (2002). Income Risk, Coping Strategies, and Safety Nets. The World Bank Research Observer, 17(2), 141-166. https://doi.org/10.1093/wbro/17.2.141

4. Deressa, T. T., Hassan, R. M., \& Ringler, C. (2010). Perception of and adaptation to climate change by farmers in the Nile basin of Ethiopia. The Journal of Agricultural Science,

5. Glennerster Rachel, Michael Kremer, Isaac Mbiti and Kudzai Takavarasha, Access and Quality in the Kenyan Education System:, (2011).53. A Review of the Progress, Challenges and Potential Solutions; GoK Press

6. Hassan, R., and Nhemachena, C. (2008), Determinants of African Farmers' strategies for adapting to Climate Change: Multinomial Choice Analysis, AfJARE Vol 2, No.1, March2008, page 83-104.

7. Holzkämper, A. (2017). Adapting Agricultural Production Systems to Climate Change-What's the Use of Models? Agriculture, 7(10), 86. https://doi.org/10.3390/agriculture7100086

8. IPCC (2007) Climate Change 2007: Impacts, Adaptation and Vulnerability. Contribution of Working Group II to the Fourth Assessment Report of the Intergovernmental Panel on Climate Change [Parry, ML, Hanson CE (eds.)]. Cambridge University Press, Cambridge, United Kingdom and New York, NY, USA

9. Jaetzold, R., Schmidt, H., Hornetz, B. \& Shisanya, C.A. (2007). Farm Management Handbook of Kenya Vol 2 (2nd Edition): Central Kenya. Natural conditions and farm management information. Ministry of Agriculture and GTZ, Nairobi.

10. Kaguongo, W., Gildemacher, p., Demo, p., Wagoire, W. Kinyua, P., Andrade, J., Forbes, G., Thiele, G., and fugile, K. (2007). Farmers practices and adoption of improved potato varieties in Kenya and Uganda. Maastridit School of management. Kampala

11. Limo W. K., 2013; Factors influencing climate change adaptation among tea farmers in Chebut catchment area, Nandi central district, Kenya, un published MA Theses, University of Nairobi

12. Malik,A, Xin Qin and Stephen C. Smith (2010) . Autonomous Adaptation to Climate Change: A Literature Review; IIEP Working Paper 2010-24 August 20, 2010; Elliott School of International Affairs George Washington University 1957 E Street, N.W., Suite 502 Washington, D.C. 20052

13. Mikalitsa, S. (2010). Gender-specific constraints affecting technology use and household food security inwestern province of Kenya. African Journal of Food, Agriculture, Nutrition and Development, 10(4). https://doi.org/10.4314/ajfand.v10i4.55327

14. Muriithi DI. (2020). Climate variability and crop farming; analysis of adaptation strategies among small scale farmers in Nyandarua County of Kenya; Ongoing Phd Thesis; University of Nairobi

15. Ngigi, M.W., (2017); Managing risk under climate change in Kenya Multiple shocks, poverty, gender, and potential for group-based approaches, Un published PhD Theses, University of Hohenheim, Germany 
16. Oluoko-Odingo, A.A. 2011. Vulnerability and adaptation to food insecurity and poverty in Kenya. Annals of the Association of American Geographers 101 (1): 1-20. https://doi.org/10.1080/00045608.2010.532739

17. Omwoyo F. and Akivaga P. 2005 “Comprehensive geography of form two students in Kenya”, Longhorn Publishers (U) Ltd, Kampala, Uganda.

18. Rakib, M., \& Matz, J. A. (2014). The Impact of Shocks on Gender-differentiated Asset Dynamics in Bangladesh. IFPRI Discussion Paper. IFPRI Discussion Paper 01356. Washington, DC, USA.

19. Sarwary, M., Senthilnathan, S., Vidhyavathi, A., \& Kokilavani, S. (2020). Socio-economic Impact of Climate Change, Adaptation and Determinants of Willingness to Pay for Crop Insurance in Central Agro climatic Zone of Afghanistan. Current Journal of Applied Science and Technology, 83-92. https://doi.org/10.9734/cjast/2020/v39i1630739

20. Sen, L. T. H., Bond, J., Winkels, A., Linh, N. H. K., \& Dung, N. T. (2020). Climate change resilience and adaption of ethnic minority communities in the upland area in Thừa Thiên-Huế province, Vietnam. NJAS - Wageningen Journal of Life Sciences, 92, 100324. https://doi.org/10.1016/j.njas.2020.100324

21. Simotwo, H. K., Mikalitsa, S. M., \& Wambua, B. N. (2018). Climate change adaptive capacity and smallholder farming in Trans-Mara East sub-County, Kenya. Geoenvironmental Disasters, 5(1), 5. https://doi.org/10.1186/s40677-018-0096-2

22. Stefan Trueck STR. Logit Model What Are Neural Networks ?,” no. 1993; 2015.

23. Thoai TQ, Rañola RF, Camacho LD, Simelton E. Determinants of farmers' adaptation to climate change in agricultural production in the central region of Vietnam," Land Use Policy. 2018;70:224- 231

24. Wambua, B. N., Omoke, K. J., \& Mutua, T. M. (2014). Effects of Socio-Economic Factors on Food Security Situation in Kenyan Dry lands Ecosystem. 02(01), 8.

25. Wambua, B. N. (2008). Food Insecurity in Semi-Arid Areas: An analysis of socio-economic and Institutional factors with reference to Makueni District, Kenya. Ph.D Thesis, Department of Geography, University of Nairobi, Kenya 